\title{
Ameliorative activity of medicinal plant fraction for neuroprotection against acrylamide-induced neurotoxicity in Drosophila melanogaster-a comparative study
}

G. K. Pratap, Danagoudar Ananda, Chandrashekhar G. Joshi and Manjula Shantaram*

\begin{abstract}
Background: Medicinal plant extracts used in folk medicine seem to be crucial since those are generally accepted by people without worrying about the toxicity. In our present study, we have compared the neuroprotective role of the rhizome of Curculigo orchioides Gaertn. and leaf extracts of Olea dioica Roxb., against acrylamide-induced neurotoxicity in Drosophila melanogaster.

Results: In-vivo neurotoxic study was carried out using 7-day-old flies (wild-type D. melanogaster). Prior to co-after exposing the flies with acrylamide $(8 \mathrm{mM})$ along with or without OLE- 2 and $\mathrm{CU}-3$ fractions $(0.2,0.4$ and $0.6 \% \mathrm{w} / \mathrm{v})$, the heads of flies of both the control and treated groups were homogenized for biochemical assay. ACR-treated groups have shown higher elevation in AChE, SOD, LPO, and CAT activity when compared to control and treated (plant fraction) groups. Biochemical and histopathology studies show that both the plant fractions (OLE-2 and CU-3) have neuroprotective action against acrylamide.

Conclusion: The present study has demonstrated that dietary supplementation with plant fraction of OLE- 2 and CU-3 has increased antioxidant enzymes and decreased AChE activity in D. melanogaster. This activity could be part of the probable mechanisms of action by which OLE-2 and CU-3 fractions have extended the lifespan and locomotory activity in fruit flies. These fruit flies continue to provide an exciting system for metabolic studies and should be more extensively exploited. Based on these results, further studies on the identified bioactive compounds from these two plants are being planned.
\end{abstract}

Keywords: Drosophila melanogaster, Curculigo orchioides Gaertn., Olea dioica Roxb., Histopathology, Anticholinesterase activities, Medicinal plant

\footnotetext{
*Correspondence: manjula59@gmail.com

Department of Studies and Research in Biochemistry, Jnana Kaveri Post

Graduate Centre, Mangalore University, Chikka Aluvara, Kodagu 571 232,

Karnataka, India
} 


\section{Background}

Acrylamide (ACR), a water-soluble vinyl monomer group, is formed in the production of polymers used in cosmetics, pulp, paper and food industries and wastewater management (Dearfield et al., 1988). ACR also has a significant application in the research laboratory in gel electrophoretic separation of molecules.

Neurotoxicity is one of the main consequences of exposure to acrylamide, whose neurotoxicity manifestations are characteristic weight loss, muscle weakness, degeneration of the axon and nervous system (LoPachin \& Gavin, 2012). Some studies have shown autonomic, sensory, motor deficits resulting from the thalamus in experimental animals (Mehri et al., 2014). Acrylamide causes some alterations in the neurotransmitters released in the brain region, neurofilament distribution, demyelination of neurons, loss of body weight, reduction in RBC cells and haemoglobin level (Adewale et al., 2015; Imai \& Kitahashi, 2012).

Medicinal plant extracts are being used from ancient times to treat a range of diseases including diabetes, cancer, skin diseases and cardiovascular diseases (Adewale et al., 2015). The rising popularity of plant bioactive compounds as an alternative to synthetic drugs is primarily because they are generally regarded as safe, affordable, easily accessible (Priyadarshini et al., 2010), ethnically acceptable form of health solutions and trusted by a number of people (Adewale et al., 2015; Prasad \& Muralidhara, 2012). There are some plant bioactive compounds like Geraniol, Quercetin, Curcumin and Gallic acid which have natural flavonoid and phenolic compounds with antioxidant, and neuroprotective activity in neurodegenerative disease models (Niveditha et al., 2017).

Olea dioica Roxb., a member of the Oleaceae family, is an important ethnomedicinal plant and grows in open, evergreen forests at 1100-1200 m and is distributed throughout the Western Ghats region. Its plant parts such as roots, bark and leaves are used for anticancer, antioxidant, febrifuge, anti-AChE activity (Ashwathanarayana \& Naika, 2017; Pratap \& Shantaram, 2020; Pratap et al., 2020b).

Curculigo orchioides Gaertn is an ethnomedicinal plant that belongs to Hypoxidaceae family found in India and China. It has been used to alleviate human ailments like neurodegenerative diseases, bronchitis, diarrhoea, antiAChE activity (Pratap et al., 2020a) improve memory and learning, etc., (Sharma et al., 2007).

D. melanogaster has been used as one of the best models for human diseases. In addition, these flies have other advantages, namely, easy to handle, shortened lifespan, increased oxidative stress sensitivity, learning and memory defects. Recently, its usage has been comprehensive to check the effectiveness of ayurvedic medicines and their action at the molecular level (Haddadi et al., 2014).

In the present study, D. melanogaster was used to study the neuroprotective activities in plant fractions (OLE-2 and CU-3) against acrylamide. Our results recommend that these two medicinal plants may be used as sources of neuroprotective agents.

\section{Methods \\ Chemicals}

ATCI (Acetylthiocholine iodide), DTNB, acrylamide, EDTA, TBA, SDS, TCA, DCFD, ethanol were sourced from Merck company.

\section{Drosophila strain}

D. melanogaster (Wild-type, Oregon K.) strain was obtained from Drosophila stock centre, Dept. of Zoology, Mysore University, Mysuru. The Drosophila were maintained on standard wheat media supplemented with dry yeast granules at $24 \pm 2{ }^{\circ} \mathrm{C}$ and $60-80 \%$ humidity.

\section{Collection of plant material}

Rhizomes of C. orchioides Gaertn. and Olea Dioica Roxb (Leaves) were collected from the Western Ghat region of Madikeri (Lat:12.55817, Lng: 75.95315), Kodagu, Karnataka, India. The sample was authenticated by Dr. S. Leelavathi, Dept. of Botany, University of Mysore, Mysore, Karnataka, India. The specimen voucher number for the C. orchioides Gaertn is UOMBOT20CO01 and Olea dioica Roxb is UOMBOT20CO02. After authentication, medicinal plant was collected in bulk and taken for further studies. Ethanolic and methanolic extracts were subjected to column chromatography eluting with hexane and ethyl acetate in the ratio of 3:2 (Ethanolic extracts of rhizome) and chloroform and methanol in the ratio of 9:1 (methanolic leaf extracts). We have collected 15 fractions, and particularly a second fraction of the leaf extract and the third fraction of the rhizome extract showed good antioxidant (Pratap et al., 2020b), antimicrobial and anti-AChE activity (Pratap et al., 2020a).

\section{Preliminary study for selection of acrylamide concentration for treatment of Drosophila flies}

An initial study for the selection of an appropriate concentration of acrylamide to treat flies was done as per Prasad and Muralidhara (2012) with a slight modification (Prasad \& Muralidhara, 2012). D. melanogaster flies were exposed to different concentrations of acrylamide $(0,2$, $4,6,8,10 \mathrm{mM})$ in the diet for 24 and $48 \mathrm{~h}$ to verify the lethality. They were monitored frequently for the incidence of locomotor and mortality deficits. Based on the preliminary result, $8 \mathrm{mM}$ concentration was chosen as 
suitable for treatment. The exposure of flies to acrylamide for seven days induced locomotor deficits and lethality. The modulatory effect was assessed by treating with plant fractions containing phytoconstituents of OLE-2 (Olea Dioica Roxb. leaf fraction) and CU-3 (Curculigo orchioides Gaertn rhizome fraction). Seven-day-old flies of D. melanogaster were co-exposed to acrylamide $(8 \mathrm{mM})$ with or without OLE-2 and CU-3 fractions (0.2, 0.4 and $0.6 \% \mathrm{w} / \mathrm{v}$ ) in the medium. Lethality was recorded every 24 and $48 \mathrm{~h}$, while locomotory dysfunction was assessed on day1 and 2. Flies from control and treated groups were subjected to negative geotaxis assay (50 flies per group/3 replicates) to assess the extent of locomotory deficits.

\section{OLE-2 and CU-3 plant fraction concentrations for dietary supplement for flies}

A preliminary study for the selection of plant extract concentrations for dietary supplement for flies was done following the method of with a slight modification (Hosamani \& Muralidhara, 2009; Niveditha et al., 2017; Prasad \& Muralidhara, 2012; Rzezniczak, et al., 2011). To determine suitable concentrations of OLE- 2 and CU-3 plant fractions for feeding experiment and the duration of exposure required, each plant fraction diet supplement population ( $n=50$ male flies) was split into six groups, including control and treated groups. The fly diet was supplemented with $0.01,0.04,0.2,0.4,0.6,0.8$ and $1 \%(\mathrm{w} / \mathrm{v})$ plant extract and three replicates were used for each experiment. Based on the data, three concentrations of plant fractions were selected $(0.2 \%, 0.4 \%$ and $0.6 \%$; $/ \mathrm{v})$, and the survival rates were compared between control and treated flies. Three concentrations of plant fractions represent lower and higher concentrations to measure the neuroprotective effect on ACR-induced changes in negative genotoxicity assay. The higher concentration of plant fractions ( 0.8 and $1 \%(\mathrm{w} / \mathrm{v}))$ show the same neuroprotection activity. Hence, $0.6 \%(\mathrm{w} / \mathrm{v})$ was chosen as an ideal concentration.

\section{Treatment}

Seven-day-old male flies of $D$. melanogaster were coexposed to acrylamide $(8 \mathrm{mM})$ as per prasada et al, with a slight modification (Hosamani \& Muralidhara, 2009; Niveditha et al., 2017; Prasad \& Muralidhara, 2012). For every tested group, three (3) replicates of 50 flies were tested with or without OLE- 2 and CU-3 fraction (0.2, 0.4 and $0.6 \% \mathrm{w} / \mathrm{v}$ ) in the medium. Briefly, transferred 7 (seven) day-old flies into vials (Bottle) containing $10 \mathrm{ml}$ of media with $8 \mathrm{mM} \mathrm{ACR}+$ plant fraction (OLE-2 and CU-3) and kept for 7 (seven) days. Flies were transferred into a new medium for neuroprotection studies once in every two days, and after each ACR exposure, the experimental

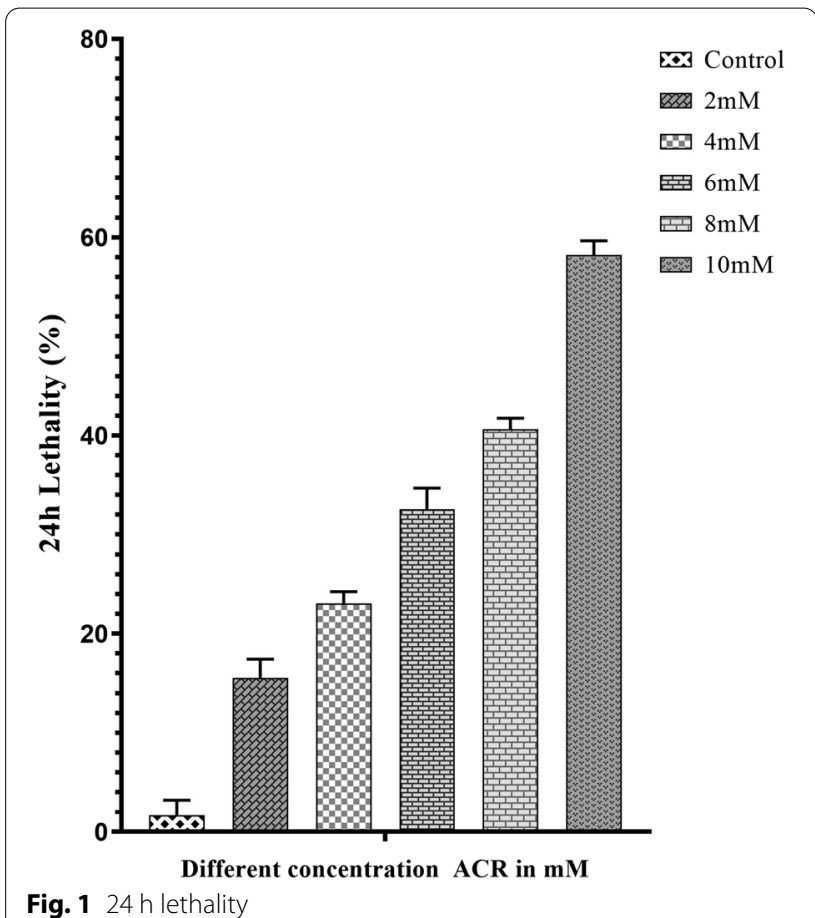

groups were maintained at $25 \pm 1{ }^{\circ} \mathrm{C}$ and $60-80 \%$ humidity. Later, the Drosophila flies from both control and treatment groups were subjected to biochemical assays.

\section{Biochemical assay}

\section{Tissue preparation}

Fly heads from control and treated groups were homogenized in ice-cold PBS (sodium phosphate buffer, $0.1 \mathrm{M}$, pH7.0), cold centrifuged at $2500 \mathrm{~g}$ for $5 \mathrm{~min}$. and the supernatant was used for biochemical assay.

\section{ROS assay}

ROS levels measured by fluorometric method of Black with a slight modification (Black \& Brandt, 1974; Haddadi et al., 2014). The microplate containing $50 \mu \mathrm{L}$ of the supernatant of sample and $15 \mu \mathrm{L}(5 \mu \mathrm{M})$ DCFH-DA was made up to $135 \mu \mathrm{L}$ by adding homogenizing buffer, and the mixture was incubated for $1 \mathrm{~h}$ at RT. The microplate was read at $489 \mathrm{~nm}$ excitation and $525 \mathrm{~nm}$ emission by Spectro-fluorometer.

\section{Lipid peroxidation (LPO) assay}

LPO assay was performed following Buege and Aust with slight modifications (Buege \& Aust, 1976; Haddadi et al., 2014). The homogenized sample $(50 \mu \mathrm{L})$ was added to the test tube containing a reaction mixture of $200 \mu \mathrm{L}$ of SDS solution (8.1\%), $1.3 \mathrm{ml}$ of acetic acid (20\%) $1.3 \mathrm{~mL}$ of TBA $(0.8 \%)$ and $150 \mu \mathrm{L}$ of milli $\mathrm{Q}$ water. The reaction mixture 
Table 1 Modulatory effect of OLE-2 and CU-3 plant fractions on antioxidant enzyme activities in the head of adult male D. melanogaster co-exposed with acrylamide (ACR) at the end of 7 days

\begin{tabular}{|c|c|c|c|c|c|c|c|c|}
\hline Assays & Control & ACR & $\begin{array}{l}\text { ACR + OLE-2 } \\
(0.2 \% \mathrm{w} / \mathrm{v})\end{array}$ & $\begin{array}{l}\text { ACR + OLE-2 } \\
(0.4 \% \mathrm{w} / \mathrm{v})\end{array}$ & $\begin{array}{l}\text { ACR + OLE-2 } \\
(0.6 \% \mathrm{w} / \mathrm{v})\end{array}$ & $\begin{array}{l}A C R+C U-3 \\
(0.2 \% w / v)\end{array}$ & $\begin{array}{l}A C R+C U-3 \\
(0.4 \% w / v)\end{array}$ & $\begin{array}{l}A C R+C U-3 \\
(0.6 \% \mathrm{w} / \mathrm{v})\end{array}$ \\
\hline $\mathrm{LPO}^{\mathrm{a}}$ & $4.94 \pm 0.691$ & $6.16 \pm 0.152$ & $6.10 \pm 0.100$ & $5.57 \pm 0.315$ & $5.67 \pm 0.050$ & $5.73 \pm 0.115$ & $5.20 \pm 0.005$ & $5.14 \pm 0.112$ \\
\hline Catalase $^{b}$ & $13.7 \pm 0.173$ & $15.6 \pm 0.208$ & $14.21 \pm 0.037$ & $12.67 \pm 0.301$ & $7.59 \pm 0.353$ & $15.25 \pm 0.015$ & $13.52 \pm 0.205$ & $11.63 \pm 1.479$ \\
\hline $\mathrm{AChE}^{\mathrm{C}}$ & $124.6 \pm 6.429$ & $162.6 \pm 2.081$ & $150.6 \pm 2.309$ & $149 \pm 1$ & $145.6 \pm 0.577$ & $153.6 \pm 2.081$ & $151.6 \pm 0.577$ & $149 \pm 1$ \\
\hline
\end{tabular}

Data analysed by one-way ANOVA followed by Tukey's test for comparison of control, ACR ( $8 \mathrm{mM})$ and co-exposed with ACR + plant fractions at different concentrations Mean \pm SD

a Lipid peroxidation (LPO), MDA $\mathrm{nM} / \mathrm{mg}$ protein

${ }^{b}$ Catalase, $\mathrm{nmol}$ of $\mathrm{H}_{2} \mathrm{O}_{2} / \mathrm{min} / \mathrm{mg}$ protein

${ }^{\mathrm{c}} \mathrm{AChE}, \mathrm{nM} / \mathrm{min} / \mathrm{mg}$ protein

was properly mixed and incubated for one hour at $60{ }^{\circ} \mathrm{C}$ and then cooled, which then was added to $1.5 \mathrm{~mL}$ of butanol and further incubated for $1 \mathrm{~h}$ and centrifuged for $5 \mathrm{~min}$ at $8000 \mathrm{~g}$. The yellowish supernatant was read at $\mathrm{OD}$ at $532 \mathrm{~nm}$.

\section{Catalase activity}

Catalase activity was checked following the protocol of Haddadi with a slight modification (Haddadi et al., 2014). The homogenized sample $(50 \mu \mathrm{L})$ was added to the reaction mixture contains $150 \mu \mathrm{L}\left(8 \mathrm{mM}, \mathrm{H}_{2} \mathrm{O}_{2}\right)$ and $50 \mu \mathrm{L}$ of PBS $(50 \mathrm{mM}, 7.0 \mathrm{pH})$, and the OD was read at $240 \mathrm{~nm}$.

\section{AChE activity}

Acetylcholinesterase (AChE) activities were determined by the Ellman method (Akinyemi et al., 2017; Ellman, 1959; Haddadi et al., 2014). The $50 \mu \mathrm{L}$ of the homogenized sample contains $300 \mu \mathrm{l}$ of $1.04 \mathrm{mM}$ DTNB (Ellman's Reagent). The reaction mixture was initiated by adding of $200 \mu \mathrm{L}$ of $0.83 \mathrm{mM}$ AChI and $450 \mu \mathrm{L}$ sodium phosphate buffer $(0.5 \mathrm{M}, \mathrm{pH} 8)$ and incubated for $5 \mathrm{~min}$. The reaction mixture measured at $412 \mathrm{~nm}$ in a spectrophotometer (UV-visible, Beckman Coulter, USA). AChE activity was expressed as $\mathrm{nmol} / \mathrm{min} / \mathrm{mg}$ protein.

\section{Climbing assay}

Locomotor activity and the climbing assay were performed as per Lee (Hwang et al., 2013; Lee et al., 2010; Valéria et al., 2014) with a slight modification. Spontaneous locomotion was measured on the sixth day. Ten male flies were introduced to labelled vertical climbing assay chamber $(50 \mathrm{~cm}$ in length and $2 \mathrm{~cm}$ in diameter), and the Drosophila were tapped down to the bottom of the tube and counted the number of flies that have climbed to the top of the column in $20 \mathrm{~s}$ (five trials were carried out for each group at 5-min intervals) and the number of flies reaching the top of the column against the total number of flies (Climbing Scores) as well as those that remained below the mark were counted separately.

\section{Moving behavior}

Initially, a single Drosophila was placed inside the Petri plate to assess its moving behavior (Finelli et al., 2004; Singh et al., 2017; Mathew \& Krishnamurthy, 2018; O'Keefe \& Denton, 2018). Moving behavioral studies were carried out for both treated and untreated groups.

\section{Histopathology studies}

The flies were anaesthetized, fixed in Carnoy's fixative at $4{ }^{\circ} \mathrm{C}$ overnight. After the fixation of the flies' heads, the fly sample were dehydrated in alcohol (40-100\%) and the heads were embedded in paraffin wax. Sections of $4 \mu \mathrm{m}$ thick heads were stained with $\mathrm{H}-\mathrm{E}$ stain (Kucherenko et al., 2010). The stained fly sections were observed under a light microscope (Olympus) for neuroanatomical studies to confirm the internal morphology of the flies' head sections, which showed a distinct pattern of brain degeneration in the hippocampus and optical lobe region.

\section{Protein estimation}

The protein concentration of homogenized sample was determined by Lowry's method using BSA standard (Lowry, 1951). The sample was incubated with FC phenols in alkaline condition for 30 (thirty) min and the absorbance was read at $750 \mathrm{~nm}$ using a spectrophotometer (Beckman Coulter, USA).

\section{Results}

\section{ACR-induced lethality response}

ACR co-exposure to flies ( 24 and $48 \mathrm{~h}$ ) resulted in a timeand concentration-dependent lethality (Figs. 1, 2). Minor mortality was observed at lower to higher concentrations of ACR at $48 \mathrm{~h}$, higher concentration of ACR $(2-10 \mathrm{mM})$ showed cumulative mortality (Fig. 3).

A considerable mortality was observed when treated with ACR for 7 days. The plant fractions (OLE-2 and CU-3) improved the survival of flies against ACR toxicity than the control group. The flies fed with plant fractions exhibited dose-dependent survival against ACR toxicity. 
The percentage (\%) survival of plant fraction-treated flies was significantly higher compared to ACR-treated group, so it can be inferred that the OLE-2 and CU-3 plant fractions were effective against ACR toxicity. Based on efficient doses against acute ACR-toxicity, 0.2, 0.4 and $0.6 \%$ were used as the best concentrations to compare the neuroprotective action of the plant fractions against ACR. The ACR-induced neural dysfunctions and oxidative stress after seven-day ACR exposure flies fed with 0.2, 0.4 and $0.6 \%$ of OLE- 2 and CU-3 plant fractions showed better survival than the different fly group fed with the plant fraction. The OLE-2 and CU-3 fractions showed neuroprotective action against ACR-induced mortality in flies (Fig. 3), and the flies in CU-3 fraction showed higher neuroprotective action and survivability activity compared to OLE-2.

\section{Geotaxis assay and moving behavior}

Locomotor-deficit flies exposed to ACR resulted in cruel locomotor destruction as evident from the negative geotaxis assay. Flies were transferred into the glass column; in each climbing activity, 10 flies were introduced into a vertical glass bottle or column. The flies lean to stay at the base of the vertical glass column which showed injurious locomotor effect of ACR on the climbing capability. Dietary supplementation of the plant fraction helped improve the locomotor deficit caused by exposure to ACR (Fig. 4). The protective action of CU-3 plant fraction on climbing ability of flies was higher compared to that of OLE-2 plant fraction. However, CU-3 fraction is preferable for defence against ACR-causing locomotor injury compared to OLE-2 plant fraction. The CU-3 plant fraction-treated group showed better moving behavior and higher distance cover compared to OLE-2 plant fraction-treated groups. Better moving behavior of flies was observed compared to ACR-treated group (Fig. 5).

\section{Oxidative stress markers}

ACR-treated flies indicate a remarkable elevation in Reactive Oxygen Species ROS (Fig. 6), LPO (Fig. 7) and catalase (Fig. 8) levels. All the four fly groups fed with the plant fraction of OLE-2 and CU-3 showed declining levels of ROS, catalase, AChE and lipid peroxidation when compared to the untreated groups. The CU-3 fraction caused higher reduction in ROS, catalase and LPO levels followed by OLE- 2 fraction. Also, the administration of OLE-2 and CU-3 fractions caused a remarkable reduce in LPO and ROS levels compared to untreated groups. Treatment of OLE-2 and CU-3 fraction decreased the catalase content. The neuroprotective action of $\mathrm{CU}-3$ fraction was higher than that of OLE-2 fraction. CU-3
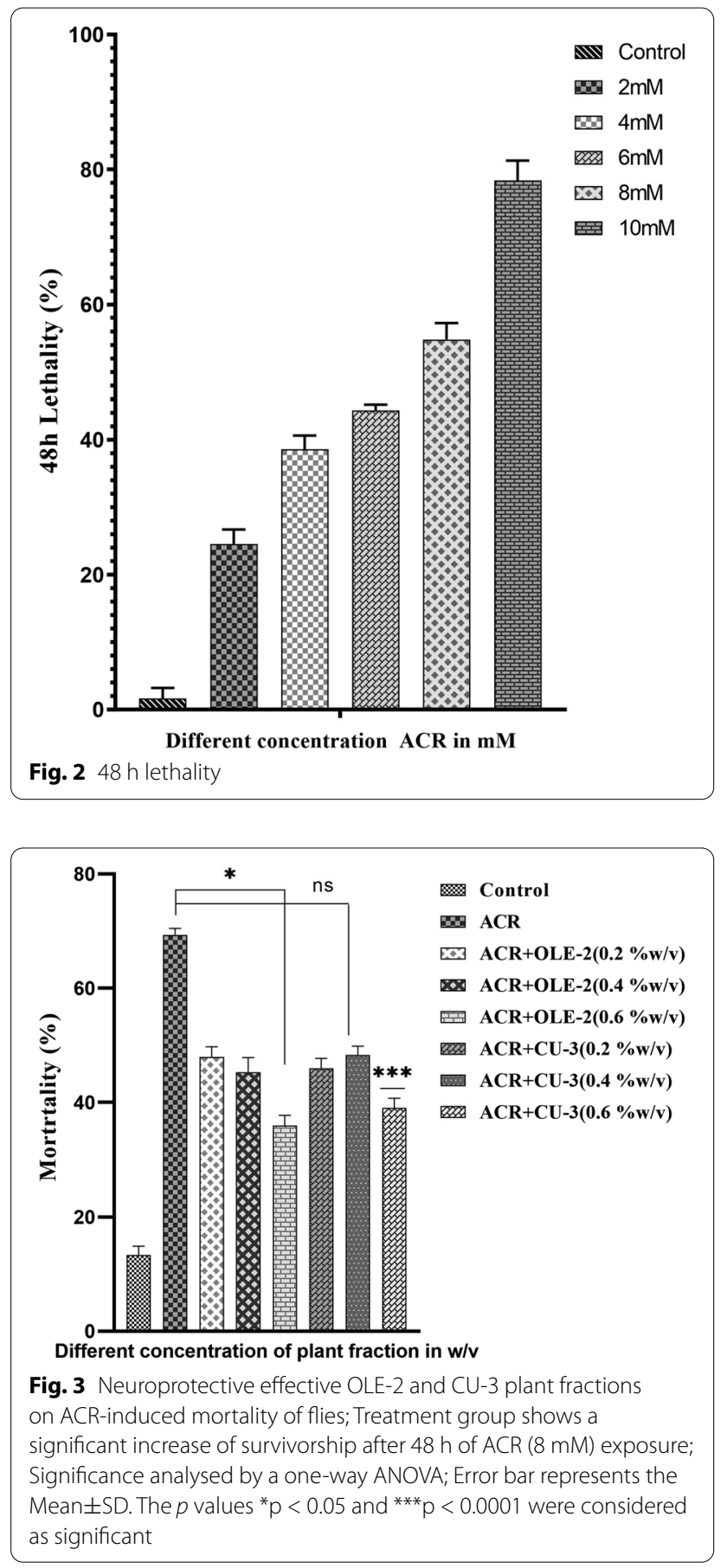

fraction was more effective in the prevention of ROS, catalase, and LPO (Table 1).

\section{Acetylcholinesterase (AChE)}

The AChE activity was significantly increased when exposed to ACR but dietary supplementation of plant fractions of OLE-2 and CU-3 altered or prevented it 
(Fig. 9). Among the two fractions, the CU-3 fraction had higher effect in the avoidance of changes in acetylcholinesterase activity than with OLE-2 fraction.

\section{Histopathology analysis}

Haematoxylin-eosin-stained histopathological sections of the D. melanogaster fly head were made ready. Flies treated with ACR $(8 \mathrm{mM})$ along with various concentrations of plant fractions (OLE-2 and CU-3) showed lesser gap in their brain indicating that these plant fractions provided neuroprotective support against ACR. The plant fraction treated fly's brain showed less neuronal loss compared to the control groups (Fig. 10).

\section{Discussion}

Acrylamide is water-soluble, and, as a result, is quickly absorbed and distributed throughout the body (Besaratinia \& Pfeifer, 2007). ACR significantly increases the production of oxidative stress and lipid peroxidation in the body. Humans are continuously exposed to low levels of acrylamide through the eating of processed carbohydrates (Kommuguri et al., 2014). It is very important to investigate regular food components which can alleviate the likely neurotoxicity. Intake of acrylamide is reported in western countries to an average daily in the range of $0.2-1.4 \mathrm{mg} / \mathrm{kg}$ body weight for adults and about $3.4 \mathrm{mg} / \mathrm{kg} \mathrm{BW}$ for children (Dybing et al., 2005). Further, daily intake of acrylamide-caused the neurotoxicants $40 \mathrm{mg} / \mathrm{kg} \mathrm{BW/}$ day (Tardiff et al., 2010). Fruit fly models are highly useful in the primary molecular mechanisms in different human neurodegenerative diseases (Feany, 2010). In recent times, use of fruit fly is considered as the best model.

The present study showed that the OLE-2 and CU-3 fraction-infused diet supplement improved the antioxidant property in $D$. melanogaster model.

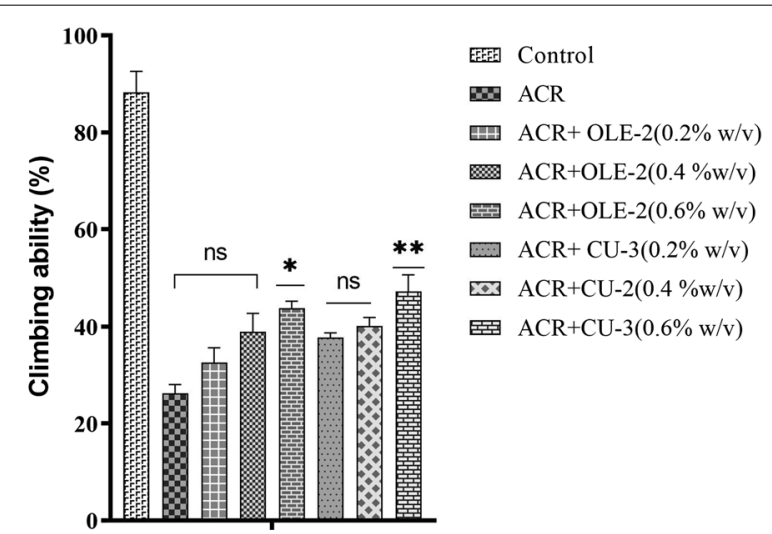

Different concentration of plant compound (w/v)

Fig. 4 Climbing assays can be used to examine the locomotor activity of co-exposed of ACR + plant fraction flies compared with control and treated groups. Plant fraction showed (OLE-2 and CU-3) improvement in the climbing ability. Significance analysed by one-way ANOVA. Error bar represents the Mean $\pm \mathrm{SD}$. The $p$ values ${ }^{*} p<0.05$ and ${ }^{* *} p<0.01$ were considered as significant while comparing ACR treated group and co-exposed to ACR + plant fraction group

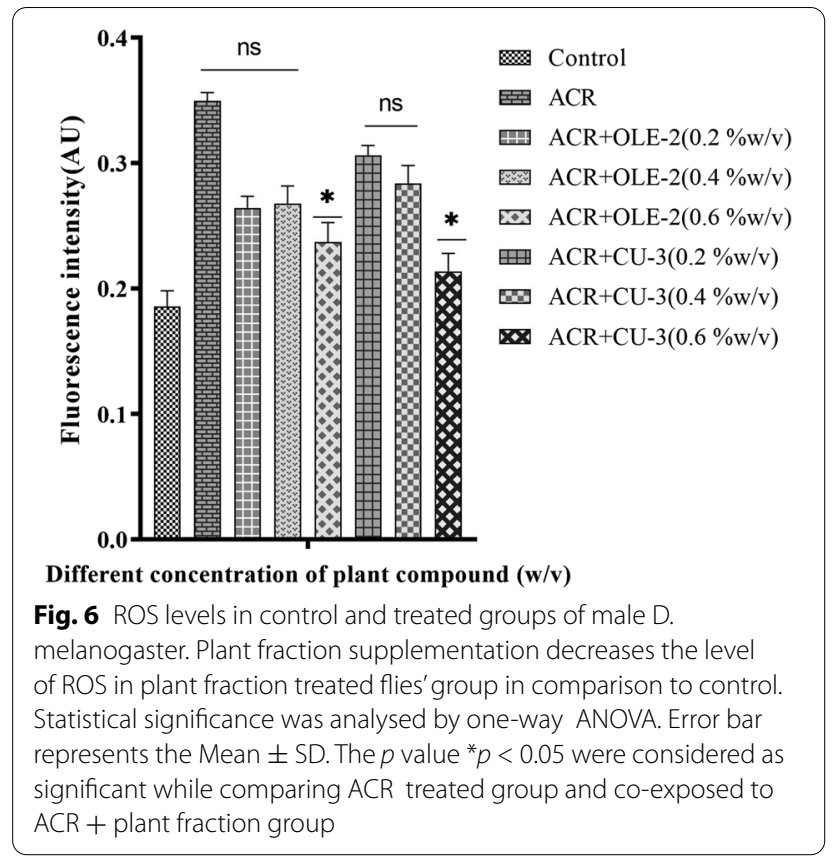

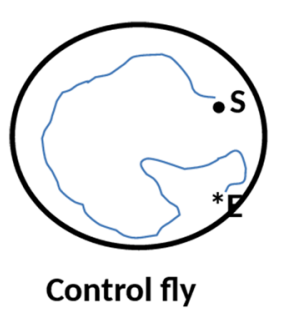
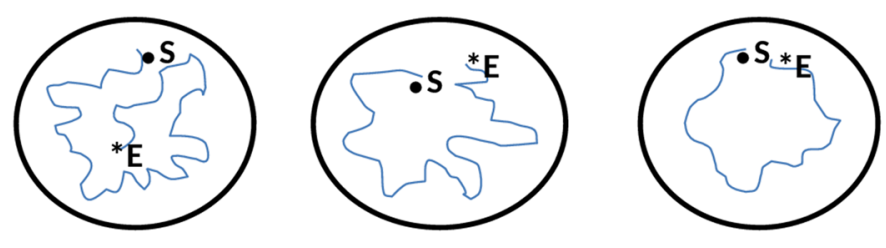

\section{ACR treated fly $A C R+$ OLE-2 Plant fraction ACR+ CU-3 Plant fraction}

Fig. 5 Moving behaviour control and ACR and ACR + plant fraction treated fly, ACR treated fly move irregularlycompared to ACR + plant treated fraction groups showed less irregular movement. ' $S$ ' is the starting point of fly, 'E' is theend point of fly 

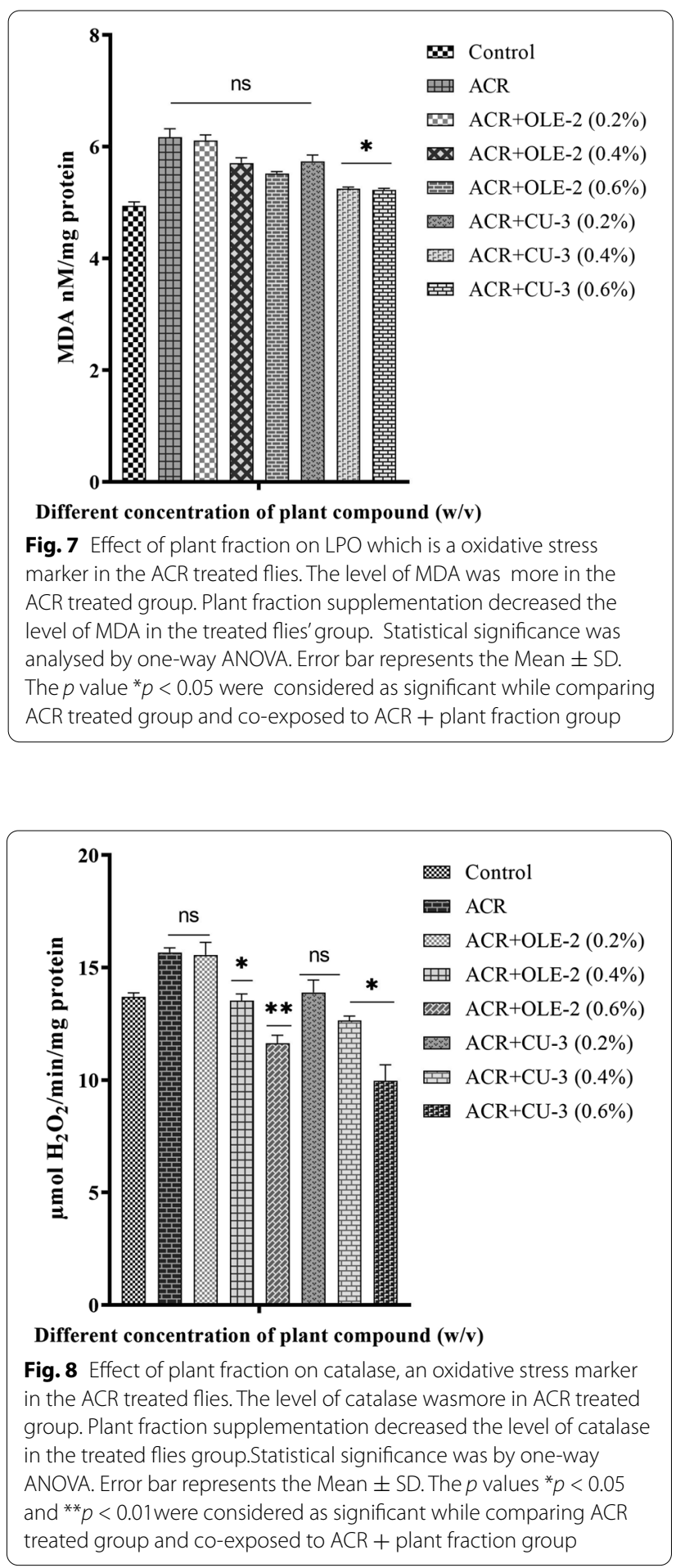

The reduction in the action of antioxidant and superoxide dismutase in the ACR-treated flies and the administration of OLE- 2 and CU-3 could reverse these effects to the level found in controls. The ability of plant fraction of OLE-2 and CU-3 to inhibit lipid peroxidation in the

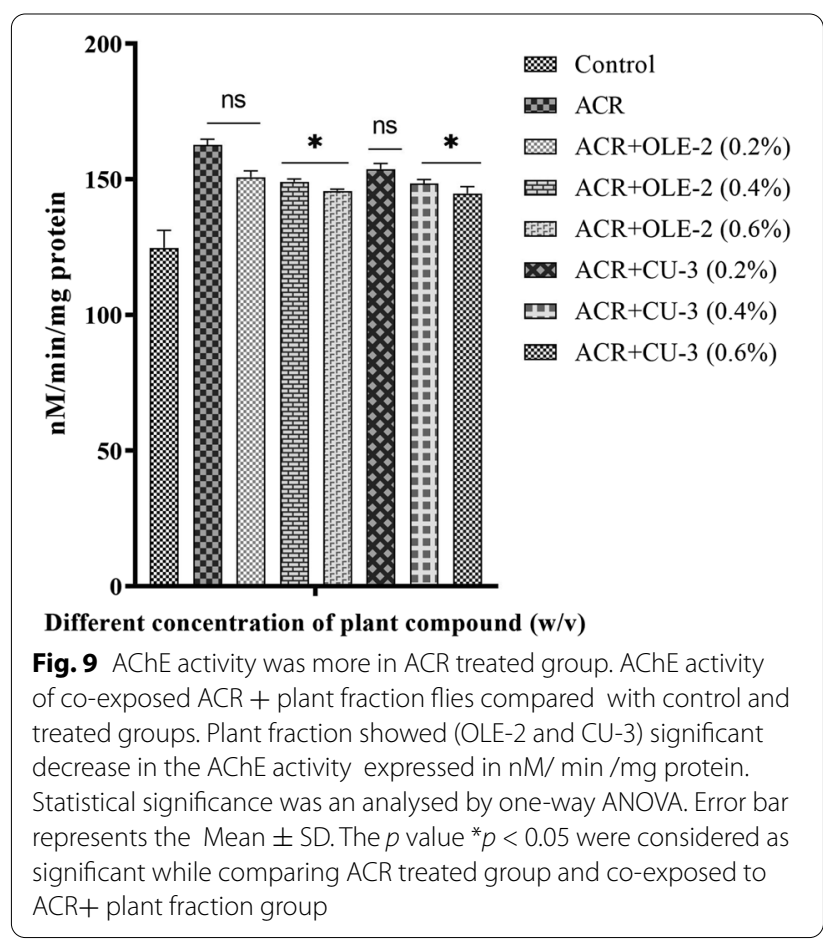

flies of acrylamide-treated group has been increased. The plant fractions could inhibit membrane lipid peroxidation thereby preventing free radical scavenging or by the enhancement of the activity of glutathione (Deiana et al., 2011)

We studied the consequence of acrylamide in fruit fly head regions. Acrylamide effect CNS and PNS system in both higher animals and humans (Pennisi et al., 2013). Studies that describe the neuroprotective effects of OLE- 2 and CU-3 fractions in the D. melanogaster system are limited.

Thus, the plant fractions are indicative of their ability to suppress oxidative stress, hence the capability to reduce ACR neurotoxicity. The plant fractions (OLE-2 and CU-3) suppressed ACR-induced oxidative stress as conspicuous from the decline in the LPO and ROS level, and enhanced lifespan and climbing activity. ACR-treated fruit flies with plant fraction-supplemented diet showed a reduction in the activity of LPO, catalase and ROS.

Acetylcholine is a neurotransmitter of the cholinergic system and plays an significant role in modulating functions such as learning, memory and locomotory activities (Deiana et al., 2011). It has some significant role in cholinergic system in neurodegenerative diseases like Alzheimer's and Parkinson's disease (Zhang et al., 2013). Our study showed that plant fraction-supplemented diet caused decrease in AChE activity significantly when compared to control groups. 


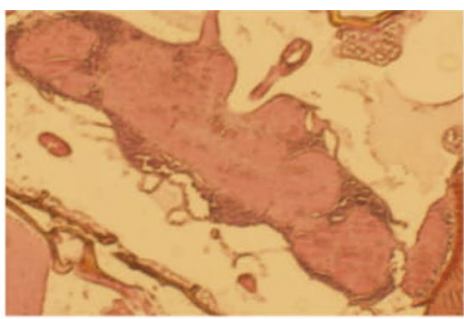

Control

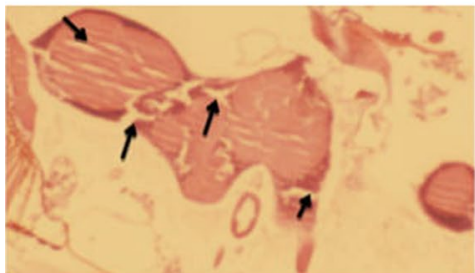

$\mathrm{ACR}+\mathrm{OLE}-2(0.2 \%)$

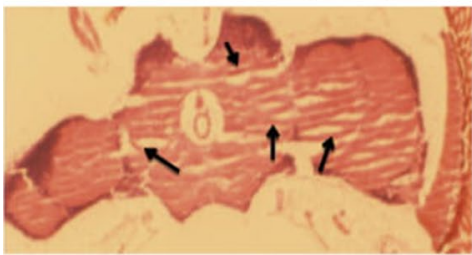

$\mathrm{ACR}+\mathrm{CU}-3(0.2 \%)$

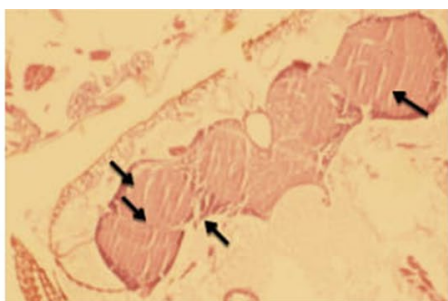

$\operatorname{ACR}(8 \mathrm{mM})$

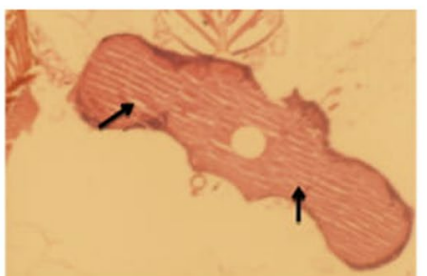

$A C R+O L E-2(0.4 \%)$

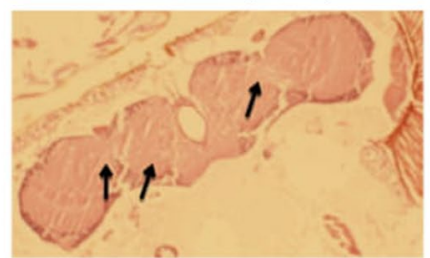

$\mathrm{ACR}+\mathrm{CU}-3(0.4 \%)$

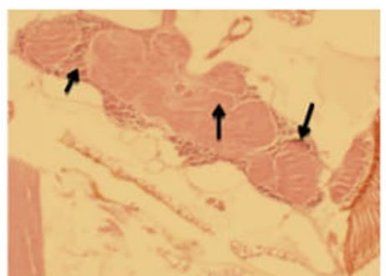

$A C R+O L E-2(0.6 \%)$

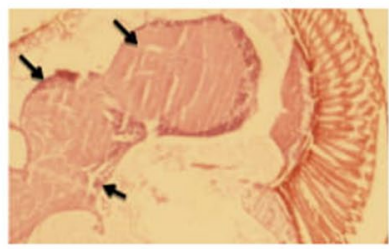

$\mathrm{ACR}+\mathrm{CU}-3(0.6 \%)$

Fig. 10 The control fly's brain showed no vacuolated areas and no tissue gaps in central body complex but ACR treated fly brain showed more tissue gap in central and optical lobe, more over ACR + plant fraction (OLE-2 and CU-3) treated group showed less vacuolated areas and tissue gap compared to ACR treated group

The plant fractions working in our study showed altering degrees of neuroprotection against ACR and showed no variation in their action. The neuroprotective effect of plant fractions was comparable to that of $\mathrm{CU}-3$ which was better than that of OLE-2 fraction against ACRinduced oxidative stress. Our study shows that the neuroprotection of OLE-2 and CU-3 fractions may act via reduction in oxidative stress, LOP and AChE activity, which are implicated in neuronal dysfunction. Hence, we surmize that OLE-2 and CU-3 fractions are possible to provide major neuroprotection against acrylamideinduced neurotoxicity and neuropathy in fly models (LoPachin \& Gavin, 2008, 2012).

\section{Conclusion}

Plant fractions (OLE-2 and CU-3) contained some natural bioactive compounds that exhibited an increase in lifespan, antioxidant enzyme and decreased the activity of AChE. On the other hand, this may be appropriate to the synergistic effect of many plant compounds in the plant fractions. Further, the isolation and detection of active compounds should be able to consider the outlet mechanism of neuroprotective action in Oleo dioica
Roxb. and Curculigo orchioides Gaertn. The semi-purified plant fraction contains certain bioactive compounds such as tannins, phenolics, polyphenols, terpenes and flavonoids. The types of natural compounds present in the plant fractions and their concentration that protect the neurons against the acrylamide in the plant fraction are yet to be explored. In general, the bioactive compound proportion of any semi-purified plant fraction is $<1-2 \%$ and different types of plant bioactive compounds would successfully protect the neurons and thus may exhibit AChE inhibition activity.

The present study has demonstrated that dietary supplementation with plant fraction of OLE-2 and CU-3 has increased antioxidant enzymes and decreased AChE activity in D. melanogaster. This activity could be a part of the probable mechanisms of action by which OLE- 2 and CU-3 fractions have extended the lifespan and locomotory activity in fruit flies. These fruit flies continue to provide an exciting system for metabolic studies and should be more extensively exploited. Based on these results, further studies on the identified bioactive compounds from these two plants are being planned. 


\section{Abbreviations}

ATCl: Acetylthiocholine iodide; ACR: Acrylamide; AChE: Acetylcholinesterase; CAT: Catalase; CU-3: Curculigo orchioides Gaertn rhizome fraction; DCFDA: 2',7'-Dichlorofluorescin diacetate; DTNB: Dithionitrobis benzoic acid; EDTA: Ethylenediaminetetra acetic acid; LPO: Lipid peroxidation; OLE-2: Olea Dioica Roxb. Leaf fraction.

\section{Acknowledgements}

We would like to thank Drosophila melanogaster Stock Centre, University of Mysore, Mysore, for providing wild-type Drosophila melanogaster model for our studies.

\section{Authors' contributions}

This work was carried out in consultation and collaboration with all the authors. First author, PGK had designed and conducted the study. Second author AD did the data analysis. Authors CGJ and MS conceived the study and were in charge of overall directions, planning and manuscript correction. All authors read and approved the final manuscript.

\section{Funding}

Self.

\section{Availability of data and materials}

Nil.

\section{Declarations}

\section{Ethics approval and consent to participate}

Not required.

\section{Consent for publication}

Nil.

\section{Competing interests}

This manuscript has not been published and is not under consideration for publication elsewhere. We have no conflict of interest to disclose.

Received: 7 September 2020 Accepted: 15 September 2021 Published online: 02 October 2021

\section{References}

Adewale, O. O., Brimson, J. M., Odunola, O. A., Gbadegesin, M. A., Owumi, S. E., Isidoro, C., et al. (2015). The potential for plant derivatives against acrylamide neurotoxicity. Phytotherapy Research, 29(7), 978-985. https:// doi.org/10.1002/ptr.5353

Akinyemi, A. J., Oboh, G., Ogunsuyi, O., Abolaji, A. O., \& Udofia, A. (2017). Curcumin-supplemented diets improve antioxidant enzymes and alter acetylcholinesterase genes expression level in Drosophila melanogaster model. Metabolic Brain Disease. https://doi.org/10.1007/ s11011-017-0100-7

Ashwathanarayana, R., \& Naika, R. (2017). Study on antioxidant and cytotoxic properties of Olea dioica Roxb. Crude extract and its pure compound collected from Western Ghats, Karnataka, India. Asian Journal of Pharmaceutical and Clinical Research, 10(2), 356-367. https://doi.org/10.22159/ajpcr. 2017.v10i2.15727

Besaratinia, A., \& Pfeifer, G. P. (2007). A review of mechanisms of acrylamide carcinogenicity. Carcinogenesis, 28(3), 519-528. https://doi.org/10.1093/ carcin/bgm006

Black, M. J., \& Brandt, R. B. (1974). Spectrofluorometric analysis of hydrogen peroxide. Analytical Biochemistry, 58(1), 246-254. https://doi.org/10.1016/ 0003-2697(74)90464-3

Buege, J. A., \& Aust, S. D. (1976). Lactoperoxidase-catalyzed lipid peroxidation of microsomal and artificial membranes. Biochimica Et Biophysica Acta (BBA) - General Subjects. https://doi.org/10.1016/0304-4165(76)90236-1

Dearfield, K. L., Abernathy, C. O., Ottley, M. S., Brantner, J. H., \& Hayes, P. F. (1988). Acrylamide: Its metabolism, developmental and reproductive effects, genotoxicity, and carcinogenicity. Mutation Research/reviews in Genetic Toxicology. https://doi.org/10.1016/0165-1110(88)90015-2
Deiana, S., Platt, B., \& Riedel, G. (2011). The cholinergic system and spatial learning. Behavioural Brain Research, 221(2), 389-411. https://doi.org/10.1016/j. bbr.2010.11.036

Dybing, E., Farmer, P. B., Andersen, M., Fennell, T. R., Lalljie, S. P. D., Müller, D. J. G., et al. (2005). Human exposure and internal dose assessments of acrylamide in food. Food and Chemical Toxicology. https://doi.org/10.1016/j.fct. 2004.11 .004

Ellman, G. L. (1959). Tissue sulfhydryl groups. Archives of Biochemistry and Biophysics. https://doi.org/10.1016/0003-9861(59)90090-6

Feany, M. B. (2010). New approaches to the pathology and genetics of neurodegeneration. The American Journal of Pathology. https://doi.org/10.2353/ ajpath.2010.091077

Finelli, A., Kelkar, A., Song, H.-J., Yang, H., \& Konsolaki, M. (2004). A model for studying Alzheimer's Aß42-induced toxicity in Drosophila melanogaster. Molecular and Cellular Neuroscience. https://doi.org/10.1016/j.mcn.2004. 03.001

Haddadi, M., Jahromi, S. R., Sagar, B. K. C., Patil, R. K., Shivanandappa, T., \& Ramesh, S. R. (2014). Brain aging, memory impairment and oxidative stress: A study in Drosophila melanogaster. Behavioural Brain Research, 259, 60-69. https://doi.org/10.1016/j.bbr.2013.10.036

Hosamani, R. (2009). Neuroprotective efficacy of Bacopa monnieri against rotenone induced oxidative stress and neurotoxicity in Drosophila melanogaster. Neurotoxicology. https://doi.org/10.1016/j.neuro.2009.08.012

Hwang, S., Song, S., Hong, Y. K., Choi, G., Suh, Y. S., Han, S., et al. (2013). Drosophila DJ-1 decreases neural sensitivity to stress by negatively regulating daxx-like protein through dFOXO. PLOS Genetics. https://doi.org/10.1371/ journal.pgen.1003412

Imai, T., \& Kitahashi, T. (2012). A 13-week toxicity study of acrylamide administered in drinking water to hamsters. Journal of Applied Toxicology. https:// doi.org/10.1002/jat.2831

Kommuguri, U. N., Satyaprasad Pallem, P. V., Bodiga, S., \& Bodiga, V. L. (2014) Effect of dietary antioxidants on the cytostatic effect of acrylamide during copper-deficiency in Saccharomyces cerevisiae. Food and Function, 5(4), 705-715. https://doi.org/10.1039/c3fo60483g

Kucherenko, M. M., Marrone, A. K., Rishko, V. M., Yatsenko, A. S., Klepzig, A., \& Shcherbata, H. R. (2010). Paraffin-embedded and frozen sections of drosophila adult muscles. Journal of Visualized Experiments. https://doi. org/10.3791/2438

Lee, K. S., Lee, B. S., Semnani, S., Avanesian, A., Um, C. Y., Jeon, H. J., et al. (2010). Curcumin extends life span, improves health span, and modulates the expression of age-associated aging genes in Drosophila melanogaster. Rejuvenation Research, 13(5), 561-570. https://doi.org/10.1089/rej.2010. 1031

LoPachin, R. M., \& Gavin, T. (2008). Acrylamide-induced nerve terminal damage: Relevance to neurotoxic and neurodegenerative mechanisms. Journal of Agricultural and Food Chemistry. https://doi.org/10.1021/jf703745t

LoPachin, R. M., \& Gavin, T. (2012). Molecular mechanism of acrylamide neurotoxicity: Lessons learned from organic chemistry. Environmental Health Perspectives. https://doi.org/10.1289/ehp.1205432

Lowry, O. H., Rosebrough, N. J., Farr, A. L., \& Randall, R. J. (1951). Protein measurement with the Folin phenol reagent. The Journal of Biological Chemistry, 193(1 PP-United States). Retrieved from https://www.ncbi.nlm. nih.gov/pubmed/14907713.

Mathew, B. B., \& Krishnamurthy, N. B. (2018). Assessment of lead toxicity using Drosophila melanogaster as a model. Journal of Clinical Toxicology. https:// doi.org/10.4172/2161-0495.1000380

Mehri, S., Karami, H. V., Hassani, F. V., \& Hosseinzadeh, H. (2014). Chrysin reduced acrylamide-induced neurotoxicity in both in vitro and in vivo assessments. Iranian Biomedical Journal. https://doi.org/10.6091/ibj.1291.2013

Niveditha, S., Shivanandappa, T., \& Ramesh, S. (2017). Ameliorative potential of natural antioxidants against paraquat-induced oxidative stress and locomotor impairment in Drosophila melanogaster: A comparative study. The Open Bioactive Compounds Journal, 5(1), 43-56. https://doi.org/10. 2174/1874847301705010043

O'Keefe, L., \& Denton, D. (2018). Using drosophila models of amyloid toxicity to study autophagy in the pathogenesis of Alzheimer's disease. BioMed Research International. https://doi.org/10.1155/2018/5195416

Pennisi, M., Malaguarnera, G., Puglisi, V., Vinciguerra, L., Vacante, M., \& Malaguarnera, M. (2013). Neurotoxicity of acrylamide in exposed workers. International Journal of Environmental Research and Public Health, 10(9), 3843-3854. https://doi.org/10.3390/ijerph10093843 
Prasad, S. N., \& Muralidhara. . (2012). Evidence of acrylamide induced oxidative stress and neurotoxicity in Drosophila melanogaster — Its amelioration with spice active enrichment: Relevance to neuropathy. Neurotoxicology. https://doi.org/10.1016/j.neuro.2012.07.006

Pratap, G. K., Rather, S. A., \& Shantaram, M. (2020a). In Vitro anti-cholinesterase activity and mass spectrometric analysis of curculigo orchioides Gaertn. rhizome extract. Analytical Chemistry Letters, 10(4), 442-458. https://doi. org/10.1080/22297928.2020.1837669

Pratap, G. K., Rather, S. A., \& Shantaram, M. (2020b). Anticholinesterase activity and mass spectral analysis of olea dioica Roxb., an in vitro study. Indian Journal of Pharmaceutical Sciences, 82, 601-611.

Pratap, G. K., \& Shantaram, M. (2020). A Kinetic study of acetylcholinesterase inhibition by fractions of Oleo diox Roxb.leaf and Curculigo orchioides Gaertn rhizome for the treatment of Alzheimer's disease. European Journal of Medicinal Plants. https://doi.org/10.9734/ejmp/2019/v30i430188

Priyadarshini, S., Ashadevi, J. S., Nagarjun, V., \& Prasanna, K. S. (2010). Increase in Drosophila melanogaster longevity due to rasayana diet: Preliminary results. Journal of Ayurveda and Integrative Medicine, 1(2), 114-119. https:// doi.org/10.4103/0975-9476.65085

Rzezniczak, T. Z., Douglas, L. A., Watterson, J. H., \& Merritt, T. J. S. (2011). Paraquat administration in Drosophila for use in metabolic studies of oxidative stress. Analytical Biochemistry. https://doi.org/10.1016/j.ab.2011.08.023

Sharma, N., Devi, S. V., \& Pandey, R. (2007). In vitro propagation of a threatened, anticarcinogenic herb, Curculigo orchioides Gaertn. Journal of Plant
Biochemistry and Biotechnology, 16(1), 63-65. https://doi.org/10.1007/ BF03321931

Singh, S. K., Srivastav, S., Yadav, A. K., \& Srikrishna, S. (2017). Knockdown of APPL mimics transgenic $A \beta$ induced neurodegenerative phenotypes in Drosophila. Neuroscience Letters. https://doi.org/10.1016/j.neulet.2017.03.030

Tardiff, R. G., Gargas, M. L., Kirman, C. R., Leigh Carson, M., \& Sweeney, L. M. (2010). Estimation of safe dietary intake levels of acrylamide for humans. Food and Chemical Toxicology. https://doi.org/10.1016/j.fct.2009.11.048

Valéria, F., Felipe, G., Echeverria, G., Raquel, M. K., Kemmerich, M. I., Lausmann, T. A., et al. (2014). Phytochemical constituents and toxicity of duguetia furfuracea hydroalcoholic extract in Drosophila melanogaster. EvidenceBased Complementary and Alternative Medicine. https://doi.org/10.1155/ 2014/838101

Zhang, X., Lu, L., Liu, S., Ye, W., Wu, J., \& Zhang, X. (2013). Acetylcholinesterase deficiency decreases apoptosis in dopaminergic neurons in the neurotoxin model of Parkinson's disease. The International Journal of Biochemistry \& Cell Biology. https://doi.org/10.1016/j.biocel.2012.11.015

\section{Publisher's Note}

Springer Nature remains neutral with regard to jurisdictional claims in published maps and institutional affiliations.

\section{Submit your manuscript to a SpringerOpen ${ }^{\odot}$ journal and benefit from:}

- Convenient online submission

- Rigorous peer review

- Open access: articles freely available online

- High visibility within the field

- Retaining the copyright to your article

Submit your next manuscript at $\boldsymbol{\nabla}$ springeropen.com 